\title{
Synthesis and Characterisation of First Row Transition Metal Complexes of Functionalized 1,2,4-Benzothiadiazines
}

E. R. Clark, M. U. Anwar, B. J. Leontowicz, Y. Beldjoudi, J. J. Hayward, W. Chan, E. L. Gavey, M. Pilkington, E. Zysman-Colman and J. M. Rawson*

\section{Supplementary Information}

Fig. S1 Solution UV/vis spectra of selected derivatives of $\mathbf{1}$, along with $\mathbf{3}$ and $\mathbf{4}$ as well as the parent ligand $\mathbf{L}$ to emphasise the ligand-based nature of the spectroscopic properties.

Fig. S2 Crystal packing of $\mathbf{1}$ in the ab plane revealing the two dimensional nature of the hydrogen-bonded motif.

Fig. S3 Experimental and simulation EPR spectra of 2 in solid-state at room temperature (295K); $g_{x x}=g_{y y}=2.054, g_{z z}=2.200(<g>=2.103), a_{x x}=a_{y y}=a_{z z}=25 G, \Delta H_{x x}=175, \Delta H_{y y}=25$, $\Delta \mathrm{H}_{\mathrm{zz}}=75 \mathrm{G}$.

Fig. S4 Curie-Weiss behaviour of 2 (left) $\left(C=0.416\right.$ emu.K.mol $\left.{ }^{-1}, g=2.103\right)$ and $\mathrm{M}$ vs $\mathrm{H}$ plot for 2 at $5 \mathrm{~K}$ (right) with the dotted line representing the fit to the Brillouin function for an $S=1 / 2$ paramagnet $(g=2.103)$.

Fig. S5 Magnetic response of 3 in the region $5 \mathrm{~K}-300 \mathrm{~K}$.

Fig. S6 X-band EPR spectrum of 4 cast in a thin film of $p-\mathrm{ClC}_{6} \mathrm{H}_{4} \mathrm{CN}$ measured at room temperature. Simulation parameters were: $g_{11}=1.950, g_{22}=g_{33}=1.994, a_{v(11)}=172 \mathrm{G}$ and $\mathrm{a}_{\mathrm{v}(22)}=\mathrm{a}_{\mathrm{V}(33)}=66 \mathrm{G}, \Delta \mathrm{H}_{\mathrm{pp}(11)}=55 \mathrm{G}, \Delta \mathrm{H}_{\mathrm{pp}(22)}=\Delta \mathrm{H}_{\mathrm{pp}(33)}=42 \mathrm{G}$ (Lorentzian lineshape). 


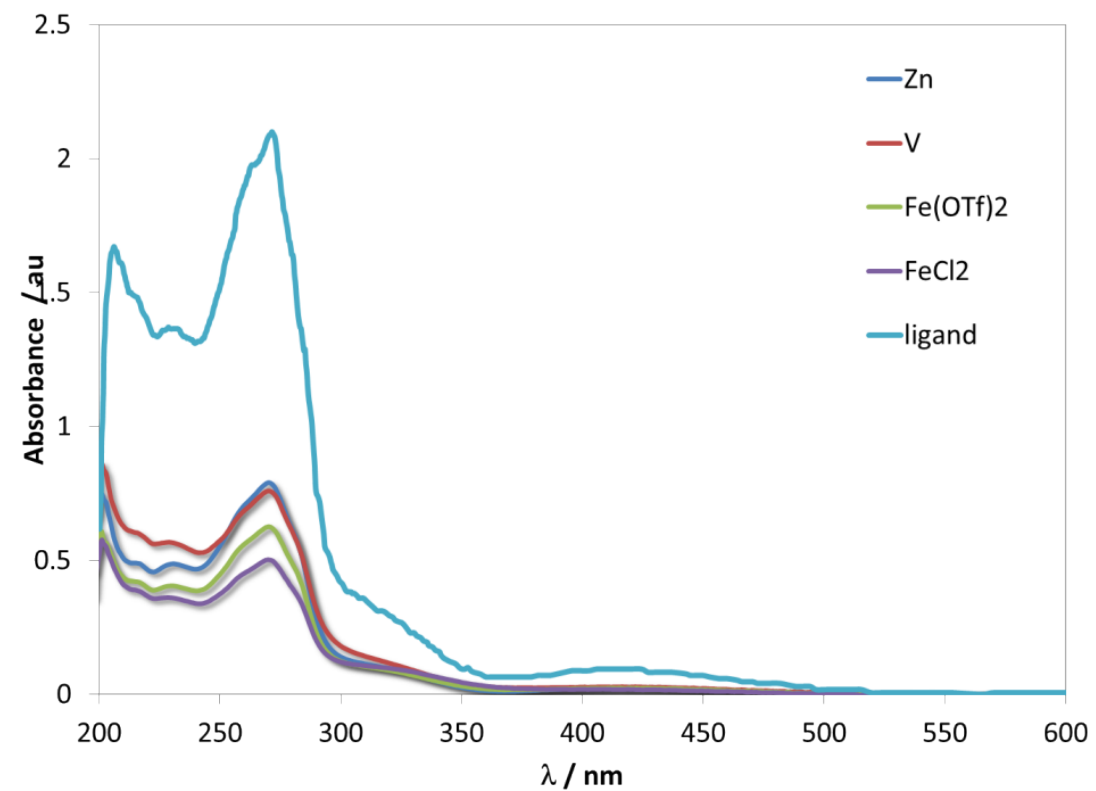

Fig. S1: Solution UV/vis spectra of selected derivatives of $\mathbf{1}$, along with $\mathbf{3}$ and $\mathbf{4}$ as well as the parent ligand $\mathbf{L}$ to emphasise the ligand-based nature of the spectroscopic properties.

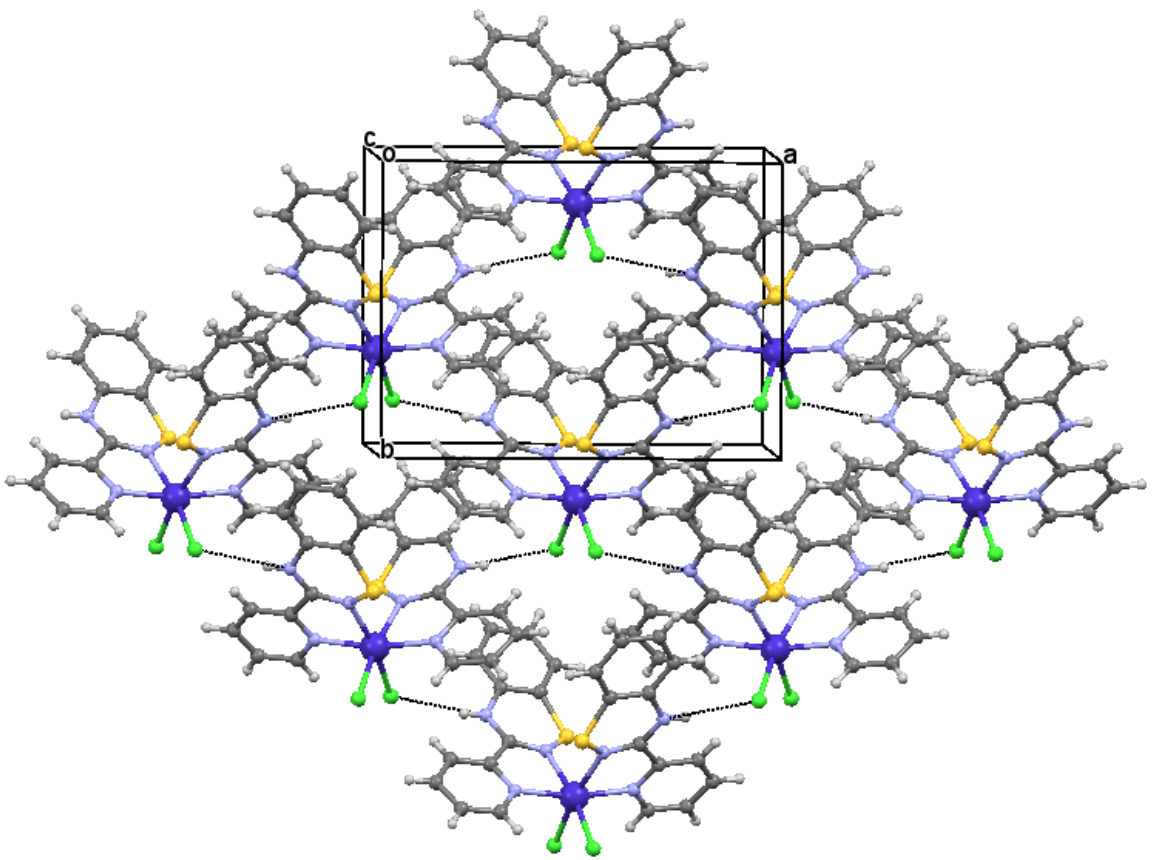

Fig. S2 Crystal packing of $\mathbf{1}$ in the $a b$ plane revealing the two dimensional nature of the hydrogenbonded motif. 


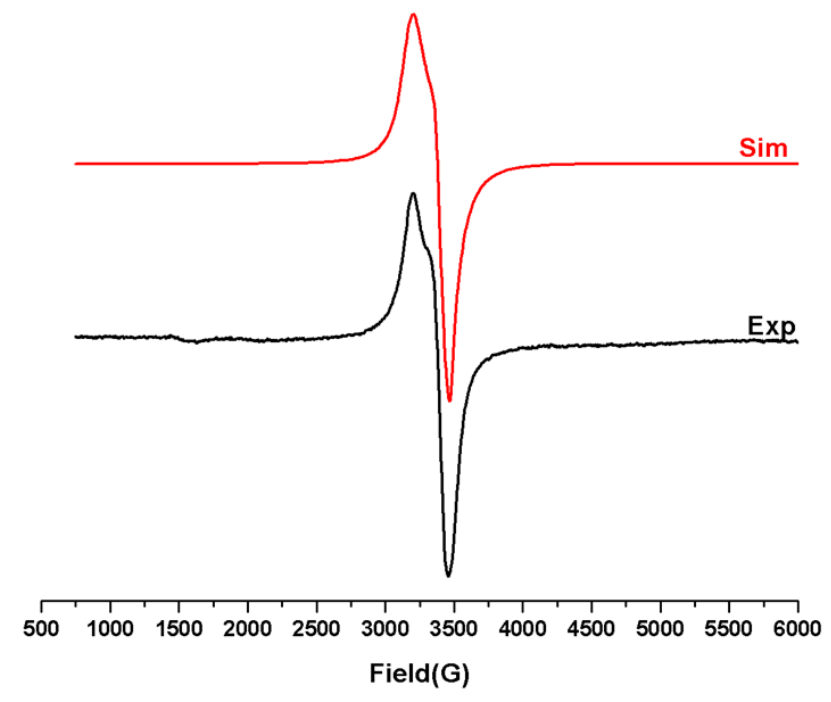

Fig. S3 Experimental and simulation EPR spectra of 2 in solid-state at room temperature (295K); $g_{x x}$ $=g_{y y}=2.054, g_{z z}=2.200\left(\langle g>=2.103), a_{x x}=a_{y y}=a_{z z}=25 G, \Delta H_{x x}=175, \Delta H_{y y}=25, \Delta H_{z z}=75 G\right.$.
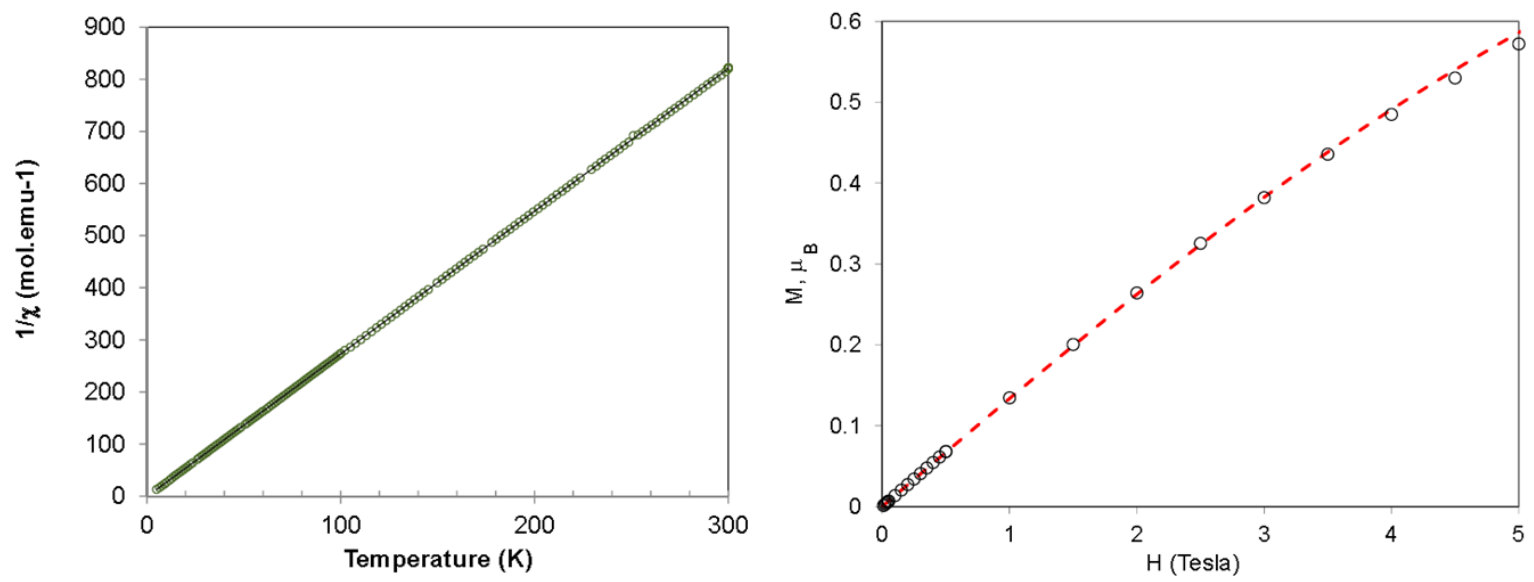

Fig. S4 Curie-Weiss behaviour of 2 (left) $\left(C=0.416\right.$ emu.K. $\left.\mathrm{mol}^{-1}, \mathrm{~g}=2.103\right)$ and $\mathrm{M}$ vs $\mathrm{H}$ plot for $\mathbf{2}$ at $5 \mathrm{~K}$ (right) with the dotted line representing the fit to the Brillouin function for an $S=1 / 2$ paramagnet $(g=2.103)$. 


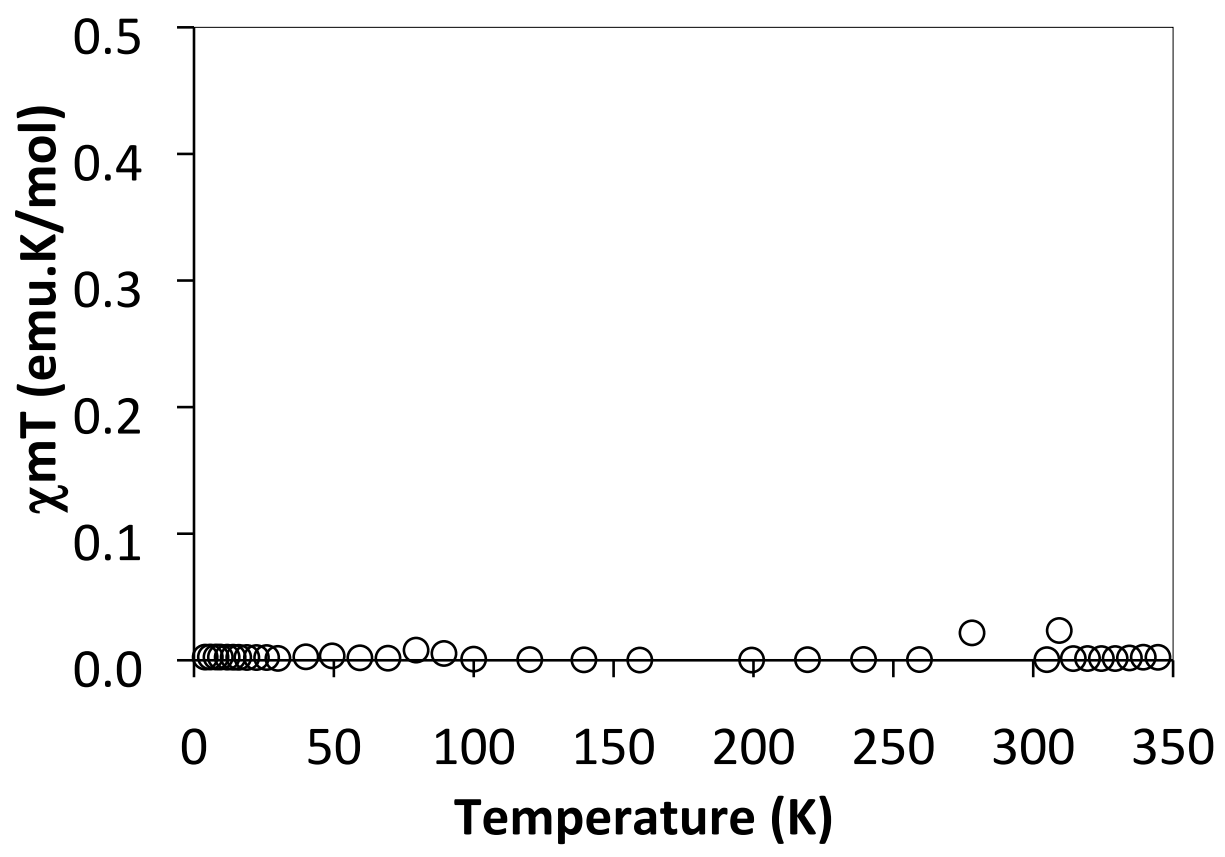

Fig. S5 Magnetic response of 3 in the region $5 \mathrm{~K}-300 \mathrm{~K}$.

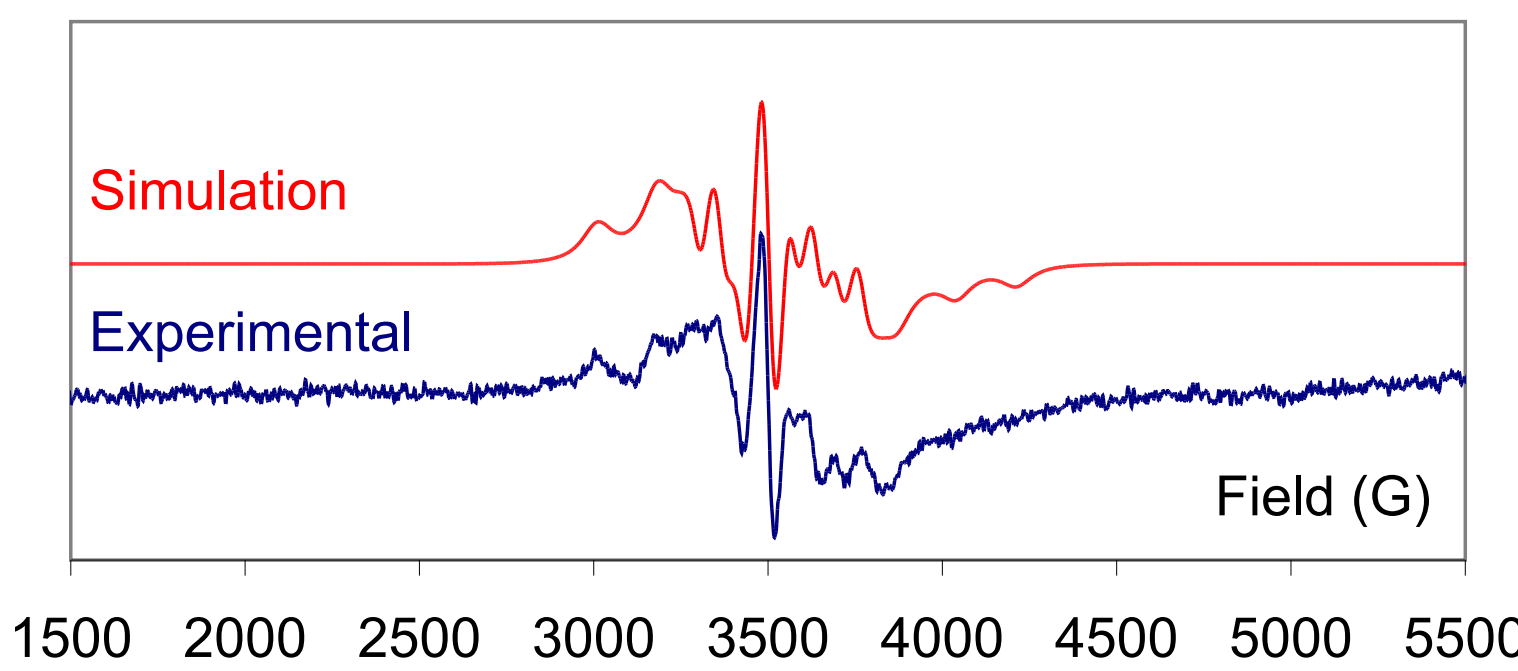

Fig. S6 X-band EPR spectrum of 4 cast in a thin film of $p-\mathrm{ClC}_{6} \mathrm{H}_{4} \mathrm{CN}$ measured at room temperature. Simulation parameters were: $\mathrm{g}_{11}=1.950, \mathrm{~g}_{22}=\mathrm{g}_{33}=1.994, \mathrm{a}_{\mathrm{V}(11)}=172 \mathrm{G}$ and $\mathrm{a}_{\mathrm{V}(22)}=\mathrm{a}_{\mathrm{V}(33)}=66$ $\mathrm{G}, \Delta \mathrm{H}_{\mathrm{pp}(11)}=55 \mathrm{G}, \Delta \mathrm{H}_{\mathrm{pp}(22)}=\Delta \mathrm{H}_{\mathrm{pp}(33)}=42 \mathrm{G}$ (Lorentzian lineshape). 